\title{
Content conceptualization and issues of solving the education system development tasks for the purposes to achieve sustainable development of the region social area
}

\author{
E.V. Bezvikonnaya, A.V. Bogdashin, T.S. Volokh, and E.V. Portnyagina \\ Omsk State Pedagogical University, Nab. Tukhachevskogo, 14, 644099 Omsk, Russia
}

\begin{abstract}
The education sector is one of the most vulnerable levels of public social management. The main contradiction here lies in the presence of a purpose to perform a social order for the creation of conditions for receiving education by various categories of citizens and market mechanisms of education relationship adjustment. In conditions of unstable environment, the development of the education strategic concept through 2035 appears to be a vital prerequisite to forecast the potential of this social management branch. Regional development context forms the required conditions for adapting the concept goals and tasks to the region social and economic development level. The impact of education at social processes in the region is expressed in the change of social order for educational services under the impact of market conditions.
\end{abstract}

\section{Introduction}

Education is the principal resource of the state social and economic development and the common weal level increase. Exactly for this reason, it is very important to have a long-term education development model, that would provide the society substantial development. On the other side, education is a system, that should be distinguished by mobility and flexibility, because it should respond to permanent and fast changes in the field of information technologies, transformations in the social field.

A strategic task of education becomes its affordability for everyone throughout life. And in connection with this, measurable quantitative and qualitative indicators, that will allow assessing the education development progress from the position of providing the stable social and economic development, should be present. In our opinion, the system of education quality state monitoring, and possibility of its implementation at the regional level, are the actual subject that rises fierce dispute. The considerable amount of attempts to look for efficient indicators of the education quality monitoring. In our opinion, any national system of education quality assessment for its conformity to state objectives and sustainable development criteria faces a problem of the possibility of this system implementation at the regional level, consideration of regional specifics.

The subject of this paper is the process of implementing a new education concept at the regional level: law and managerial aspects. Goal: based on the analysis of existing approaches 
to education modernization for the purposes to achieve sustainable development, and to offer ways of improvement.

The Draft Concept "Key Areas for Russian Education Development for Achieving the Goals and Tasks of Sustainable Development in the Education System" through 2035 [1] contains the notion of "drivers", factors able to impact at the education system development. Among all drivers, we would like to draw attention to internal and systemic drivers, because right here, the specifics of education regional development should be taken into account to the fullest extent, both in terms of monitoring modern state, and in terms of possibilities and threats. And, for regret, in this context, the potential of regions and their social and economic capabilities may differ.

By analyzing these drivers, we see that they represent the staff policy systemic problems: absence of a system of motivating high-potential young specialists; a problem of the "Internet expert" who represents information, who gives information in an understandable, fast, and bright way, and the pedagogue expert. An education expert without authority or image at the level of state policy, loses his/her positions. Not an education system, but the Internet resources become the information source.

The draft specifies important problems, such as stress manifestation in lecturers, pedagogue's work load, and formality of requirements, that decrease the level of motivation both in students and pedagogues, and do not solve the education system issues. The issue of information resources, network learning technologies, accessibility of these technologies to education organizations are also specified as the main internal system drivers [2].

Based on the analysis of external and internal drivers, it is possible to state that the specific mechanisms may be developed and implemented only at the expense of integrating possibilities and resources of various institutions into the education system and, in the whole, into the regional development system. In this instance, we may discuss various integration forms in the form of, for example, clusters.

On this basis, the main tasks in this study are:

1. Trend analysis of the modern education management model.

2. Provide insights into the content of the education state assessment indicators, that should become primary indicators.

3. Develop possible forms of network interaction between all subjects of educational relationship.

\section{Materials and Methods}

In terms of working on the study subject, the collective of authors used the institutional and systemic approaches. Analysis of projects, legislative acts, studying of expert commentaries were used as specific and empiric methods.

The systemic approach is conditioned by the education consideration from the position of the social and economic system stable development. At this, the authors take into account the specifics of regional education systems and consider factors, that may became both strong factors in achieving goals set at the level of the state policy, and threats that, in our opinion, are being insufficiently assessed in terms of the education condition assessment monitoring.

In its turn, the inadequate assessment of resources of regional education systems within their powers may lead not only to the not achievement of the set tasks, but also to destructive consequences at all levels of education implementation, affecting the interests of all subjects [3].

The authors include the region-specific analysis of the situation in the education system (using the example of the Omsk Region), and the analysis of projects and expert discussions in the realization of the education concept, into the specific and empiric methods. The analysis of activity of education and discussion sites of education organizations, aimed at the 
search of joint decisions in implementation of the set tasks, should also be included into this method.

\section{Results and Conclusions}

In our opinion, efficient shifts in the education system are possible only after the correct determination of the point A where we are. When formulating drivers int he concept draft, the large accent is made on factors, that may prevent achieving strategic tasks, i.e., external and internal threats.

In fact, a task is set to form a new generation of people who will be able to make fast decisions, have flexible thinking, are resistant to stresses, and creative. Verbally, it is put in the Concept Draft as follows, "Labor market requires people who, at the same time, have high stress resistance, mental flexibility, adaptivity and creativity, who are ready to organize independent activity in unusual conditions, as well as to teamwork in different regions and with differing standards and technological systems. The ability to implement projects in short terms and with limited resources becomes critically important, systemic thinking is required, along with leadership skills. Today, modern school does not lay such foundation in the required volume" [4].

At this, the efficient assessment, indication of education state with such indicators as: level of readiness to implementation of digital projects in education organizations, digital infrastructure, basic starting point for implementation of new forms of work; staff potential assessment (readiness to implement the set tasks, staff provision level, prospects of developing such staff and hours of their work in an educational organization with regard of payment for work, motivation, infrastructure, and image). In our opinion, this system of indicative indicators is unhinged from reality again.

Schematically, this problem can be represented as a following scheme:

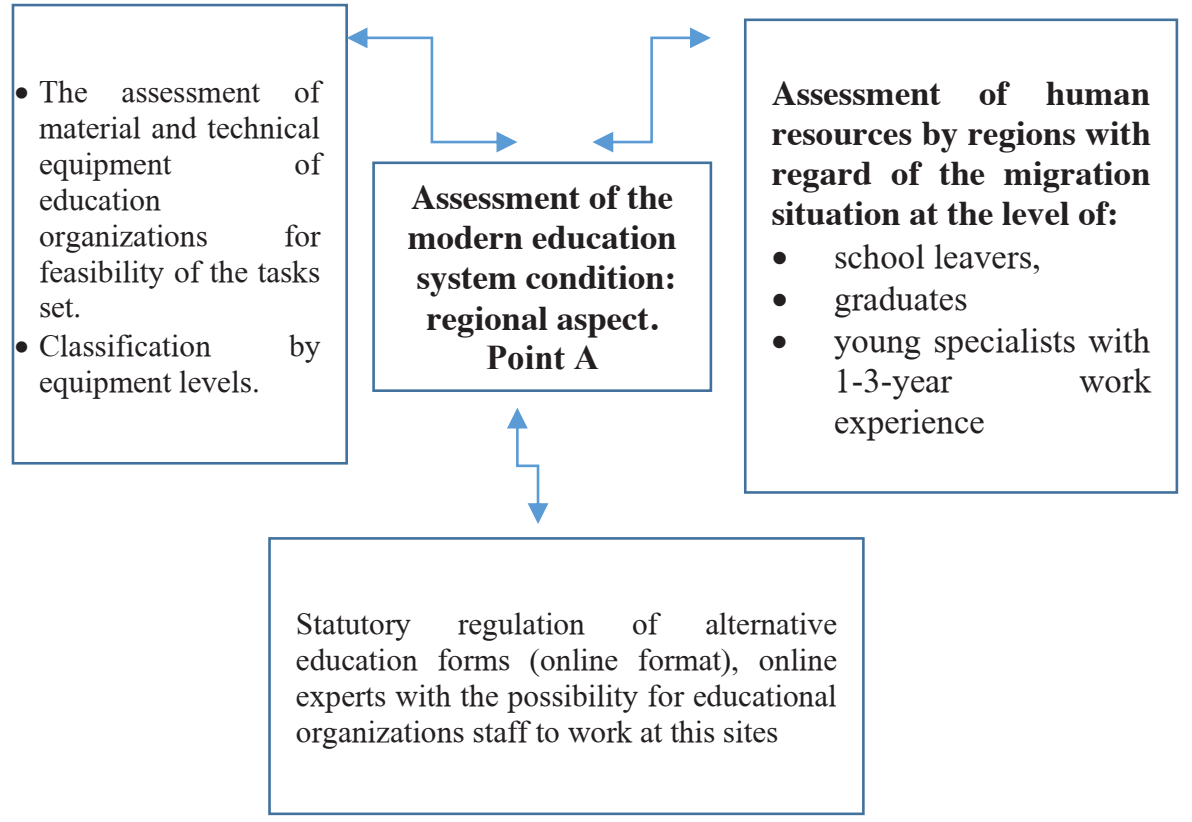

Fig. 1. Education sustainability indicators

However, in our opinion, such a factor of market relations, that have incorporated education levels and all subjects of education relationship long time ago, is omitted here. In particular, 
1. From the staff position.

1.1. High potential staff look for better conditions for self-actualization, frequently provided by an online site, registration as a self-employed entity with the possibility to implement short-term courses that give the specific skills for solving further professional tasks, personal growth.

1.2. Possibility to set the price for services independently.

1.3. Transition away from directive management, building a personal brand and selfimage.

1.4. Freedom in building an operational schedule.

That is, in the whole, we see that the main problem of human resources loss in education is low motivation and lack of prospects, including the quality material growth. At this, the market in the conditions of "pandemic" demonstrated possibilities for the realization of the potential of skilled labour, ready to use information technologies and remote education formats [5]. To which extent in these conditions the state management system is ready to law and organization regulation of these processes and their use in context of the set state tasks.

2. From the point of view of the trainees themselves.

2.1. Incomprehension of education value in the classic "school-university" variant: the state sets the task to form new competencies (emotional intelligence, flexibility, stress resistance, and the other): the final goal of applying these competencies has not been fully actualized. Considering the positioning of social networks and division into "successful" and "unsuccessful", what is the role of education in the trainee's life from the point of view of trainees themselves? Opportunism becomes one of the main features of modern school leavers.

2.2. Integration of Internet resources into the education system. The possibility to implement project activities through projects in social networks. Comprehensive realization of this direction is impossible in many schools due to trainees' digital inequality. Namely, the material and technical base outside the educational organization. Inadequacy of material and technical equipment, the standard of family living became especially obvious in the period of "pandemic" and the tranisition to remote education in regions. A contradiction appeared between the possibilities of the family, school and law resources, which assume the availability of education under any conditions.

It is just a line of sharp contradictions that are tracked, and their solution in the concept is insufficient, even at the level of understanding these problems. We should also note a problem of education management, both in the context of interaction between the management bodies and educational organizations, and the management within an educational organization.

Let us consider the problem of management within an educational organization in details. As noted in the draft concept, directivity and autocratic managerial style are inherent to the education system. Using such an instrument, as strategic sessions with the participation of pedagogic staff, many educational organizations make attempts to develop a development plan through the search of strong sides but, according to the practice of participation in such events, such factor as pedagogic staff motivation is neglected here again. Without sufficient finance resources, an educational organization moves to directivity again, establishing higher requirements to publications of teaching employees, their amount, activity indicators in the form of pedagogic events.

At this, stimulation mechanisms are insufficient. And such management concept goes to administrative management, to the position of enhancing job responsibilities within the established payment for work with small material incentive [6].

Solution of such problems and tasks, set to education, is impossible without the principal emphasis on the following issues

1. Problem of the pedagogue's, teacher's profession image. 
2. Issue of motivation and material incentive, payment for work.

3. Equality of education organizations in digital capabilities.

4. Changing the management system from autocratic style to a more constructive one.

As one of forms of solving the problems of education content and search of a modern paradigm, conforming to the market requirements, taking into account the employers' opinion, may become various forms of network compilations, for example, clusters. However, the cluster approach implementation is subordinated to regional priorities, that are unable to offer systemic solutions for the education industry. Undoubtedly, uniting resources of all subjects interested leads to reaching some concept indicators, but does not allow consolidating efforts in all branches of social field. In particular, in solving the problem of developing further education of children and adults at the expense of the "Navigator" system, the region aggravates a problem of low education quality, lack of connection with the trainee's future professional activity.

It is also required to unite higher educational establishments on various sites with employers under target requests, building proper regional strategies [7]. Target learning format appears to be in demand from the point of regional budget cost efficiency for learning under programs that guarantee the graduate's further employment. For this format promotion, it is required to form a motivation system, sufficient for professional self-definition in conditions of ever-changing environment requirements [8].

But the most challenging point of regional level of the concept implementation is the staff potential limited to low salary level, decrease of pedagogic activity prestige and the educational process bureaucratization in this implementation. The economy digitalization processes demonstrated high demand for specialists able to improve their own information and communication potential, use it for achieving the education goals. Even if the motivation mechanism of staff potential development is provided, it does not lead to its efficient use in regional educational practices.

The listed features of the process of implementation of active learning methods in further vocational education programs require the further ways of their improvement. First, material and non-material stimulation of lecturers to use active (interactive) training methods. Second, mutual instruction of these methods to lecturers of the field of further vocational education will allow increasing the frequency of their use in the educational process and improve their content. Third, the differentiated approach to selection of groups of listeners will enhance the potential of active learning methods.

The listed problem points of implementing the concept of the education field sustainable development through 2035 confirm the serious systemic contradictions, preventing the implementation of the main development drivers at the regional level of public power.

\section{Conclusions}

Following the conducted analysis of the education development sustainable development concept potential through 2035 , the following conclusions can be made.

First, realization of the project activity driver as a priority learning technology is subordinated to the presence of pedagogic staff creative potential, limited to bureaucratized management structure, causing the formalization of relations of key educational process subjects.

Second, remote technologies and network form of getting education activates the task of search for additional motivation stimuli, including the threat of losing a personal component in the educational process. A pedagogue becomes a victim of access to information technologies in conditions of digital inequality.

Third, the driver of individuality (creativity) appears to be the education development trend in conditions of permanent environment requests (of consumers). However, the 
response to challenges appears to be untimely, dependent on the education field systemic limitations. The largest potential of this education development trend is observed in the system of further education of children and adults.

Fourth, transformation of the education field management structure is aimed at the search of optimal organization management structures. The project structure appears to be the most priority, but scarcely feasible in connection with linear and functional nature of education organizations, mostly of state and municipal ownership.

Fifth, realization of innovative learning technologies requires the use of interactive methods, based on the combination of trainees' requests and capabilities of an educational organization. The situation contradiction consists in actual inequality of the educational process subjects in relation to the teaching methods use. An organization that provides education services is often incapable of satisfying the trainees' requests. The reason becomes lack of readiness to work on the conditions of market regulation mechanisms.

Sixth, personification of service consumers' requests leads to individualization of educational routes. Target training can be assessed as an optimal mechanism of achieving the balance of interests of consumers and educational organization. Individualization becomes possible only upon the condition when all the subjects have motivation to personalization of requests in the field of education.

Seventh, the education product practical applicability to the market conditions appears to be the leading education trend in conditions of the stable social and economic system. Construction of the latter becomes possible only upon the condition when all the subjects consolidate their efforts.

Eighth, the driver of activity approach in terms of implementing the educational process content acts as a supplement of applied direction, active and interactive teaching methods used.

\section{References}

1. Key Areas for Russian Education Development for Achieving the Goals and Tasks of Sustainable Development in the Education System" through 2035, https:/firo-nir.ru

2. M. A. Yarosh, Crimean Scientific Reporter, 5(11), 96 (2016)

3. E. P. Bagaeva, Modern Issues of Science and Education, 2, 83 (2021)

4. N. E. Sorokina, Innovations in further vocational and further vocational pedagogic education, 599 (2018)

5. D. Corte, Education Issues, 3, 29 (2014)

6. N. L. Ivanova, E. N. Dubinenkova,Issues of state and municipal administration, 4, 188 (2018)

7. Z. G. Bashirova, Kazan Pedagogical Journal, 2-2(115), 265 (2016)

8. O. N. Logvinova, Professional Education and Society, 1, 66 (2016) 